\title{
Residual compressive surface stress increases the bending strength of dental zirconia
}

\author{
Masanao Inokoshi ${ }^{a, b}$, Fei Zhang ${ }^{c}$, Kim Vanmeensel ${ }^{c}$, Jan De Munck ${ }^{a}$, \\ Shunsuke Minakuchi ${ }^{b}$, Ignace Naert ${ }^{a}$, Jozef Vleugels ${ }^{c}$, \\ Bart Van Meerbeek ${ }^{a, *}$
}

a KU Leuven (University of Leuven), Department of Oral Health Sciences, BIOMAT \& University Hospitals Leuven, Dentistry, Kapucijnenvoer 7, blok a bus 7001, B-3000 Leuven, Belgium

$\mathrm{b}$ Tokyo Medical and Dental University, Graduate School of Medical and Dental Sciences, Gerodontology and Oral Rehabilitation, 1-5-45 Yushima, Bunkyo, Tokyo 113-8510, Japan

c KU Leuven (University of Leuven), Department of Materials Engineering, Kasteelpark Arenberg 44, B-3001

Heverlee, Belgium

\section{A R T I C L E I N F O}

\section{Article history:}

Received 7 July 2016

Accepted 14 December 2016

Available online $\mathrm{xxx}$

\section{Keywords:}

Zirconia

Alumina sandblasting

Tribochemical silica sandblasting

Stress

Grinding

Mechanical properties

\begin{abstract}
A B S T R A C T
Objective. To assess the influence of surface treatment and thermal annealing on the fourpoint bending strength of two ground dental zirconia grades.

Methods. Fully-sintered zirconia specimens $\left(4.0 \times 3.0 \times 45.0 \mathrm{~mm}^{3}\right)$ of Y-TZP zirconia (LAVA Plus, 3M ESPE) and $\mathrm{Y}-\mathrm{TZP} / \mathrm{Al}_{2} \mathrm{O}_{3}$ zirconia (ZirTough, Kuraray Noritake) were subjected to four surface treatments: (1) 'GROUND': all surfaces were ground with a diamond-coated grinding wheel on a grinding machine; (2) 'GROUND + HEAT': (1) followed by annealing at $1100^{\circ} \mathrm{C}$ for $30 \mathrm{~min}$; (3) 'GROUND $+\mathrm{Al}_{2} \mathrm{O}_{3}$ SANDBLASTED': (1) followed by sandblasting using $\mathrm{Al}_{2} \mathrm{O}_{3}$; (4) 'GROUND + CoJet SANDBLASTED': (1) followed by tribochemical silica (CoJet) sandblasting. Micro-Raman spectroscopy was used to assess the zirconia-phase composition and potentially induced residual stress. The four-point bending strength was measured using a universal material-testing machine.

Results. Weibull analysis revealed a substantially higher Weibull modulus and slightly higher characteristic strength for ZirTough (Kuraray Noritake) than for LAVA Plus (3M ESPE). For both zirconia grades, the 'GROUND' zirconia had the lowest Weibull modulus in combination with a high characteristic strength. Sandblasting hardly changed the bending strength but substantially increased the Weibull modulus of the ground zirconia, whereas a thermal treatment increased the Weibull modulus of both zirconia grades but resulted in a significantly lower bending strength. Micro-Raman analysis revealed a higher residual compressive surface stress that correlated with an increased bending strength.

Significance. Residual compressive surface stress increased the bending strength of dental zirconia. Thermal annealing substantially reduced the bending strength but increased the consistency (reliability) of 'GROUND' zirconia.
\end{abstract}

(c) 2017 The Academy of Dental Materials. Published by Elsevier Ltd. All rights reserved.

\footnotetext{
* Corresponding author. Fax: +32 16332752.

E-mail addresses: bart.vanmeerbeek@kuleuven.be, bart.vanmeerbeek@uzleuven.be (B. Van Meerbeek). http://dx.doi.org/10.1016/j.dental.2016.12.007 0109-5641/@ 2017 The Academy of Dental Materials. Published by Elsevier Ltd. All rights reserved.
} 


\section{Introduction}

Today, dental zirconia most commonly consist of yttriastabilized tetragonal zirconia polycrystalline (Y-TZP) based on the TZ-3YE (Tosoh, Tokyo, Japan) starting powder [1]. Recently, more aging-resistant and stronger zirconia, such as Ce-TZP/Al $\mathrm{O}_{3}$ zirconia (NANOZR, Panasonic, Osaka, Japan) or $\mathrm{Y}-\mathrm{TZP} / \mathrm{Al}_{2} \mathrm{O}_{3}$ zirconia (ZirTough, Kuraray Noritake, Tokyo, Japan), have been introduced in dentistry [2].

In many cases, the dental technician needs to additionally grind the inside of the zirconia core to improve the fit of the zirconia restoration onto the tooth preparation [3]. Furthermore, a recent systematic review revealed that different mechanical surface pre-treatments are essential for the composite cement to durably bond to zirconia, this in light of an adhesive luting procedure [4]. Among them, aluminium oxide $\left(\mathrm{Al}_{2} \mathrm{O}_{3}\right)$ sandblasting or tribochemical silica sandblasting with 30 - and $110-\mu \mathrm{m}$ silica-coated $\mathrm{Al}_{2} \mathrm{O}_{3}$ particles are quite important to achieve durable bonding to zirconia [5]. However, the surface of the abraded zirconia will be transformed, i.e., constrained as well as damaged; this stress-induced transformation may influence the long-term clinical performance of zirconia restorations [3].

Several papers reported on the influence of different surface treatments on the mechanical properties of dental zirconia. However, no consensus was reached in literature whether surface treatments are detrimental for the mechanical properties of dental zirconia. Some of those studies reported an increased bending strength of zirconia [6-14], whereas others reported a decreased strength as result of surface damage produced by the surface treatments [15-18]. Moreover, the mechanical properties of surface-treated newer zirconia, such as $\mathrm{Y}-\mathrm{TZP} / \mathrm{Al}_{2} \mathrm{O}_{3}$ zirconia (and Ce-TZP/Al $\mathrm{A}_{2} \mathrm{O}_{3}$ zirconia, however not investigated in this study) have not much been studied yet. The objective of this study was therefore to evaluate the influence of different surface treatments on the bending strength of two different, i.e., Y-TZP and Y-TZP/Al $\mathrm{O}_{3}$, dental zirconia. The null hypothesis tested was that different surface pre-treatments do not influence the bending strength and consistency (reliability) of dental zirconia.

\section{Materials and methods}

Fully-sintered Y-TZP LAVA Plus (3M ESPE, Seefeld, Germany) zirconia and $\mathrm{Y}-\mathrm{TZP} / \mathrm{Al}_{2} \mathrm{O}_{3}$ ZirTough (Kuraray Noritake) zirconia were provided by the manufacturers in the form of $3.5 \times 4.5 \times 45.0 \mathrm{~mm}$ bending bars. Next, the specimens were ground to the size of $3.0 \times 4.0 \times 45.0 \mathrm{~mm}$, after which they were assigned to four surface treatments (Table 1): (1) 'GROUND': all surfaces were ground using a polymer-bonded diamondgrinding wheel (D46 SW 50-X2, Technodiamant, Almere, The Netherlands) on a grinding machine (JF415DS, Jung, Göppingen, Germany); (2) 'GROUND + HEAT': (1) followed by annealing at $1100^{\circ} \mathrm{C}$ in air for $30 \mathrm{~min}$ (Nabertherm, Germany); (3) 'GROUND $+\mathrm{Al}_{2} \mathrm{O}_{3}$ SANDBLASTED': (1) followed by sandblasting using $50 \mu \mathrm{m} \mathrm{Al} \mathrm{O}_{3}$ particles (Danville Engineering, San Ramon, CA, USA); (4) 'GROUND + CoJet SANDBLASTED': (1) followed by tribochemical silica sandblasting with $30 \mu \mathrm{m}$ silica-coated $\mathrm{Al}_{2} \mathrm{O}_{3}$ particles using CoJet (3 M ESPE). All surfaces of the bending bar received the same surface treatment.

One specimen from each surface-treated zirconia was used for micro-structural investigation using scanning electron microscopy (SEM, JSM-6610LV, JEOL, Tokyo, Japan) employing the following conditions (gold coated, $10^{-5} \mathrm{mbar}$ pressure, $15 \mathrm{kV}$ energy range, $85 \mu \mathrm{A}$ beam current, $1000 \times$ magnification, secondary electron image).

Micro-Raman spectroscopy was used to measure the monoclinic zirconia $\left(m-\mathrm{ZrO}_{2}\right)$ surface-volume fraction, and to assess the nature and extent of potential residual stress on the surface [19]. Depth-profile Raman spectra (SENTERRA, BrukerOptik, Ettlingen, Germany) were also collected from the top 20- $\mu \mathrm{m}$ material of surface-treated zirconia specimens using the following conditions: Ar-ion laser with a wavelength of $532 \mathrm{~nm}, 20 \mathrm{~mW}$ power at sample and $100 \times$ objective. The spectrum integration time was $20 \mathrm{~s}$ with the recorded spectra averaged over three successive measurements. For each specimen, at least 12 measurements were performed using a pinhole aperture of $50 \mu \mathrm{m}$. The $m-\mathrm{ZrO}_{2}$ surface-volume fraction was calculated using the equation proposed by Tabares et al. [20]:

$V_{m}=\frac{I_{m}^{181}+I_{m}^{190}}{0.32\left(I_{t}^{147}+I_{t}^{265}\right)+I_{m}^{181}+I_{m}^{190}}$

where $I_{m}$ and $I_{t}$ represent the height of the intensities of the monoclinic and tetragonal peaks, respectively, and the superscripts refer to the Raman wavenumber in $\mathrm{cm}^{-1}$. In addition, for each measurement, the Raman wavenumber of the tetragonal zirconia $\left(\mathrm{t}-\mathrm{ZrO}_{2}\right)$ band around $147 \mathrm{~cm}^{-1}$ was traced to analyze the residual surface-stress level [19] using a curve fitting software (fityk 1.2.1, Marcin Wojdyr, Warsaw, Poland) [21].

The bending strength was determined using a four-point bending test, following a modified ISO 6872 standard with an inner span of $20 \mathrm{~mm}$ and an outer span of $40 \mathrm{~mm}$. The specimens were loaded at a crosshead speed of $0.1 \mathrm{~mm} / \mathrm{min}$ until failure in a universal testing machine (Instron 4467, Instron, Bucks, UK). The bending strength results were statistically analyzed using Weibull analysis; pivotal confidence bounds were calculated using Monte Carlo simulation [22]. Different groups were compared at the B63.2 unreliability level, commonly referred to as the characteristic strength, $\sigma_{0}$, i.e., the strength for which the survival probability is $36.8 \%$. All tests were performed at a significance level of $\alpha=0.05$ using a software package R3.0 and Abrem (R Foundation for Statistical Computing, Vienna, Austria) and a custom-made script for this software. Additionally, the degree of correlation between the Raman wavenumber of the $\mathrm{t}-\mathrm{ZrO}_{2}$ band around $147 \mathrm{~cm}^{-1}$ and the bending strength was calculated for each grade using the abovementioned software.

\section{Results}

Representative SEM photomicrographs of the four surface treatments from each zirconia grade (LAVA Plus, 3 M ESPE; ZirTough, Kuraray Noritake) are shown in Fig. 1. For both zirconia grades, the 'GROUND' and 'GROUND + HEAT' treated zirconia revealed a similar microstructure. The 'GROUND $+\mathrm{Al}_{2} \mathrm{O}_{3}$ 
Table 1 - Summary of the different mechanical surface treatments.

\begin{tabular}{|c|c|}
\hline Surface treatment & Procedure \\
\hline ‘GROUND’ & $\begin{array}{l}\text { All surfaces were ground with a polymer-bonded diamond-grinding wheel (D46 SW 50-X2, } \\
\text { Technodiamant, Almere, The Netherlands) on a grinding machine (JF415DS, Jung, Göppingen, Germany). }\end{array}$ \\
\hline 'GROUND + HEAT’ & 'GROUND' followed by annealing at $1100^{\circ} \mathrm{C}$ in air for $30 \mathrm{~min}$. \\
\hline 'GROUND $+\mathrm{Al}_{2} \mathrm{O}_{3}$ SANDBLASTED’ & $\begin{array}{l}\text { 'GROUND' followed by sandblasting with } 50 \mu \mathrm{m} \mathrm{Al} \mathrm{A}_{2} \mathrm{O}_{3} \text { particles (Danville, Danville, CA, USA) for } 15 \mathrm{~s} / \mathrm{cm}^{2} \\
\text { at a distance of } 10 \mathrm{~mm} \text { with an intraoral air-abrasion device (Microetcher, Danville Engineering, Danville, } \\
\text { CA, USA). }\end{array}$ \\
\hline 'GROUND + CoJet SANDBLASTED’ & $\begin{array}{l}\text { 'GROUND’ followed by sandblasting with } 30 \mu \mathrm{m} \text { silica-coated } \mathrm{Al}_{2} \mathrm{O}_{3} \text { particles (CoJet sand, } 3 \mathrm{M} \text { ESPE, } \\
\text { Seefeld, Germany) for } 15 \mathrm{~s} / \mathrm{cm}^{2} \text { at a distance of } 10 \mathrm{~mm} \text { with an intraoral air-abrasion device (CoJet Prep, } \\
\text { 3M ESPE, Seefeld, Germany). }\end{array}$ \\
\hline
\end{tabular}

SANDBLASTED' zirconia resulted in a rougher surface than the 'GROUND + CoJet SANDBLASTED' zirconia. For 'GROUND' or 'GROUND + HEAT' treated Y-TZP/Al $\mathrm{Al}_{2} \mathrm{O}_{3}$ ZirTough (Kuraray Noritake) zirconia, dark contrast alumina particles were revealed.

All data of the Weibull analysis are graphically presented in Fig. 2. Table 2 summarizes the $m-\mathrm{ZrO}_{2}$ surface-volume fraction and the Weibull analysis for all groups. Overall, the $\mathrm{Y}-\mathrm{TZP} / \mathrm{Al}_{2} \mathrm{O}_{3}$ ZirTough (Kuraray Noritake) zirconia showed a higher $m-\mathrm{ZrO}_{2}$ volume fraction (up to $44 \mathrm{vol} \%$ ) compared to the Y-TZP LAVA Plus (3M ESPE) zirconia (up to 11 vol\%). Moreover, the $m-\mathrm{ZrO}_{2}$ in the Y-TZP LAVA Plus (3M ESPE) zirconia was not detectable after the heat treatment, whereas that of the $\mathrm{Y}$ $\mathrm{TZP} / \mathrm{Al}_{2} \mathrm{O}_{3}$ ZirTough (Kuraray Noritake) zirconia remained at 14 vol\% after the heat treatment at $1100^{\circ} \mathrm{C}$.

Weibull analysis revealed a higher Weibull modulus for $\mathrm{Y}-\mathrm{TZP} / \mathrm{Al}_{2} \mathrm{O}_{3}$ ZirTough (Kuraray Noritake) zirconia than for Y-TZP LAVA Plus (3M ESPE) zirconia, independent of the surface treatment. For Y-TZP/ $/ \mathrm{Al}_{2} \mathrm{O}_{3}$ ZirTough (Kuraray Noritake) zirconia, the highest Weibull modulus was obtained for the 'GROUND + HEAT' surface treatment, which however also corresponded to the lowest characteristic bending strength. For both zirconia grades, 'GROUND' zirconia resulted in the lowest Weibull modulus. Although the surface-treated ('GROUND', 'GROUND $+\mathrm{Al}_{2} \mathrm{O}_{3}$ SANDBLASTED' or 'GROUND + CoJet SANDBLASTED') zirconia showed a comparable characteristic strength, the 'GROUND $+\mathrm{Al}_{2} \mathrm{O}_{3}$ SANDBLASTED' and 'GROUND + CoJet SANDBLASTED' zirconia resulted in a higher Weibull modulus compared to the solely 'GROUND' zirconia. Moreover, $\mathrm{Al}_{2} \mathrm{O}_{3}$ sandblasting was more efficient in increasing the Weibull modulus than tribochemical silica (CoJet) sandblasting.

The results of the correlation analysis of the tetragonal band position around $147 \mathrm{~cm}^{-1}$ in relation to the four-point bending strength are shown in Fig. $3 a$ and b. A clear peak shift toward a higher wavelength was observed for the 'GROUND', 'GROUND $+\mathrm{Al}_{2} \mathrm{O}_{3}$ SANDBLASTED' and 'GROUND + CoJet SANDBLASTED' zirconia as compared to the 'GROUND+HEAT' zirconia. The correlation analysis revealed that a larger peak shift toward a higher wavelength, implying a higher residual compressive surface-stress level, increased the bending strength. Calculated $\mathrm{R}^{2}$ values were $0.93(p=0.0338)$ for $\mathrm{Y}-\mathrm{TZP} / \mathrm{Al}_{2} \mathrm{O}_{3}$ ZirTough (Kuraray Noritake) zirconia and $0.97(p=0.0155)$ for Y-TZP LAVA Plus (3 M ESPE) zirconia.

The residual stress evolution in the top $20-\mu \mathrm{m}$ layer of surface-treated zirconia is presented in Fig. $3 c$ and $d$ for the
Y-TZP LAVA Plus (3M ESPE) zirconia and the Y-TZP/Al $\mathrm{A}_{2}$ ZirTough (Kuraray Noritake) zirconia, respectively. 'GROUND', 'GROUND $+\mathrm{Al}_{2} \mathrm{O}_{3}$ SANDBLASTED' and 'GROUND + CoJet SANDBLASTED' Y-TZP/ $/ \mathrm{Al}_{2} \mathrm{O}_{3}$ ZirTough (Kuraray Noritake) zirconia resulted in a gradually decreasing residual compressive stress layer of up to about $8 \mu \mathrm{m}$ deep, whereas the compressive stress dropped much faster for the 'GROUND', 'GROUND $+\mathrm{Al}_{2} \mathrm{O}_{3}$ SANDBLASTED' and 'GROUND + CoJet SANDBLASTED' Y-TZP LAVA Plus (3M ESPE) zirconia within about $4 \mu \mathrm{m}$ from the surface.

\section{Discussion}

The present study focused on the influence of different surface treatments on the four-point bending strength of dental zirconia. For both the respective $\mathrm{Y}-\mathrm{TZP}$ and $\mathrm{Y}-\mathrm{TZP} / \mathrm{Al}_{2} \mathrm{O}_{3}$ zirconia grades (LAVA Plus, 3M ESPE; ZirTough, Kuraray Noritake), grinding with or without additional sandblasting resulted in a comparable but substantially higher characteristic bending strength in comparison with the heat-treated ground zirconia. The heat-treated ground zirconia however had the highest Weibull modulus, whereas sandblasting substantially increased the Weibull modulus of the ground zirconia. The $\mathrm{Y}-\mathrm{TZP} / \mathrm{Al}_{2} \mathrm{O}_{3}$ ZirTough (Kuraray Noritake) zirconia has a significantly higher Weibull modulus than the Y-TZP LAVA Plus (3M ESPE) zirconia. Therefore, the null hypothesis should be partially rejected, depending on the type of surface treatment.

In the present study, the $m-\mathrm{ZrO}_{2}$ volume fraction and the residual surface stress were assessed using micro-Raman spectroscopy. Regarding the $m-\mathrm{ZrO}_{2}$ surface-volume fraction, the heat treatment of the ground Y-TZP LAVA Plus (3M ESPE) zirconia at $1100{ }^{\circ} \mathrm{C}$ induced a $m-\mathrm{ZrO}_{2}$ to $\mathrm{t}-\mathrm{ZrO}_{2}$ phase transformation, which resulted in an undetectable level of $m-\mathrm{ZrO}_{2}$ after the heat treatment. For $\mathrm{Y}-\mathrm{TZP} / \mathrm{Al}_{2} \mathrm{O}_{3}$ ZirTough (Kuraray Noritake) zirconia, on the other hand, heat treatment at $1100^{\circ} \mathrm{C}$ only partially induced this $m-\mathrm{ZrO}_{2}$ to $\mathrm{t}-\mathrm{ZrO}_{2}$ phase transformation. This difference should probably be related to a difference in transformability of both zirconia. To confirm this assumption, we additionally assessed the transformability of $\mathrm{Y}-\mathrm{TZP} / \mathrm{Al}_{2} \mathrm{O}_{3}$ ZirTough (Kuraray Noritake) zirconia and Y-TZP LAVA Plus (3M ESPE) zirconia using micro-Raman spectroscopy, i.e., by measuring the amount of the $t-\mathrm{ZrO}_{2}$ phase transforming into $m-\mathrm{ZrO}_{2}$ upon sample fracturing. The transformability of $\mathrm{Y}-\mathrm{TZP} / \mathrm{Al}_{2} \mathrm{O}_{3}$ ZirTough (Kuraray Noritake) zirconia was around $60 \%$, whereas that of Y-TZP LAVA Plus (3M ESPE) zirconia was about $10 \%$. The higher transformability 

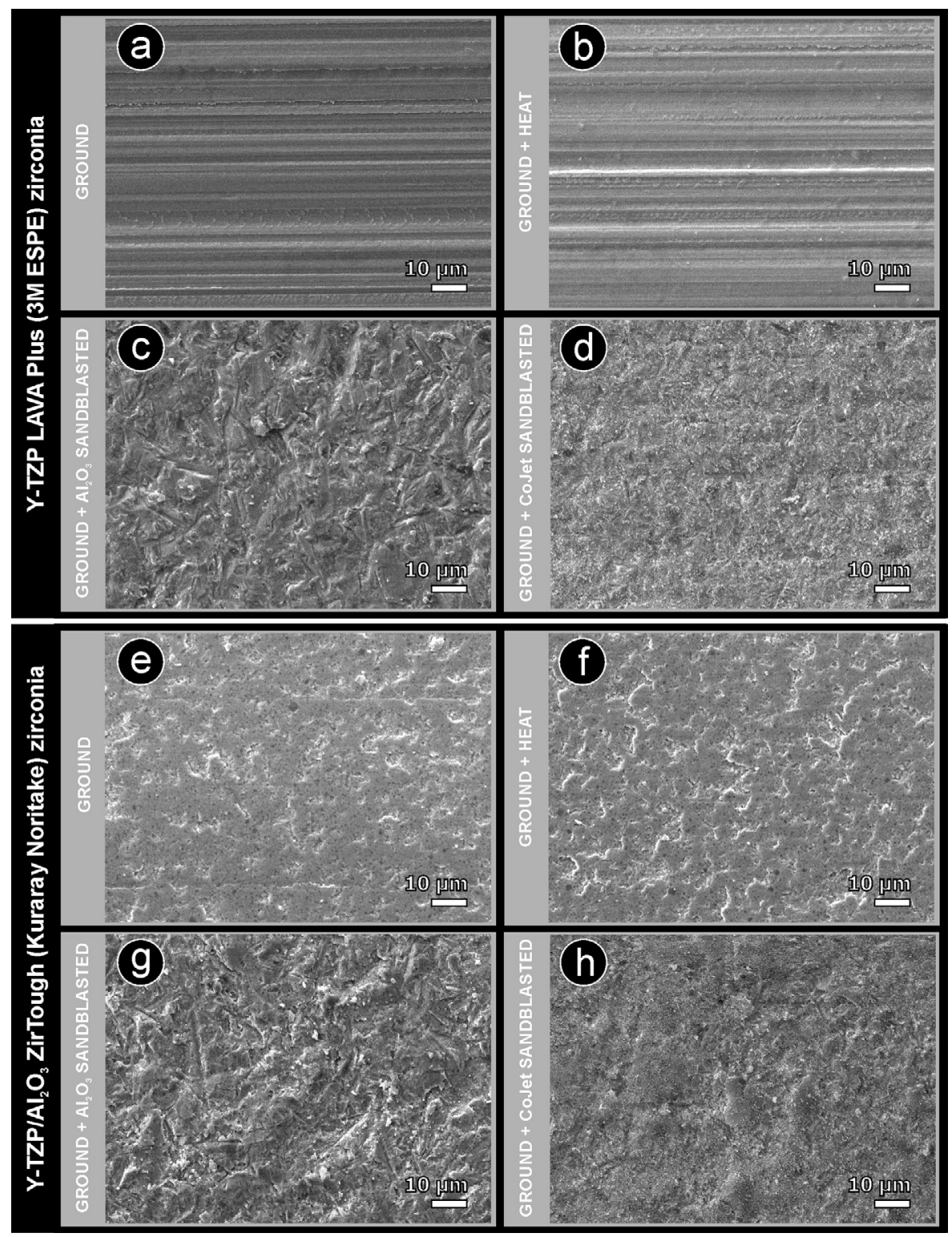

Fig. 1 - Representative SEM photomicrographs of the four surface treatments for each zirconia grade (LAVA Plus, 3M ESPE; ZirTough, Kuraray Noritake). (a) 'GROUND' and (b) 'GROUND + HEAT' treated Y-TZP LAVA Plus (3M ESPE) zirconia: for both specimens, several scratches can be observed; (c) 'GROUND + $\mathrm{Al}_{2} \mathrm{O}_{3}$ SANDBLASTED' and (d) 'GROUND + CoJet SANDBLASTED' Y-TZP LAVA Plus (3M ESPE) zirconia: ‘GROUND + $\mathrm{Al}_{2} \mathrm{O}_{3}$ SANDBLASTED' zirconia revealed a rougher surface than 'GROUND + CoJet SANDBLASTED' Y-TZP LAVA Plus (3M ESPE) zirconia. (e) 'GROUND' and (f) 'GROUND + HEAT' treated $\mathrm{Y}-\mathrm{TZP} / \mathrm{Al}_{2} \mathrm{O}_{3}$ ZirTough (Kuraray Noritake) zirconia: for both specimens, dark contrast alumina particles can be observed; (g) 'GROUND + $\mathrm{Al}_{2} \mathrm{O}_{3}$ SANDBLASTED' and (h) 'GROUND + CoJet SANDBLASTED' Y-TZP/Al $\mathrm{O}_{3}$ ZirTough (Kuraray Noritake) zirconia: the surface characteristics were similar to those observed for the 'GROUND $+\mathrm{Al}_{2} \mathrm{O}_{3}$ SANDBLASTED' and 'GROUND + CoJet SANDBLASTED’ Y-TZP LAVA Plus (3M ESPE) zirconia.

of Y-TZP/ $/ \mathrm{Al}_{2} \mathrm{O}_{3}$ ZirTough (Kuraray Noritake) zirconia resulted in a larger amount of $m-\mathrm{ZrO}_{2}$ after the surface treatment, as compared to that for Y-TZP LAVA Plus (3M ESPE) zirconia. Apparently, a temperature of $1100^{\circ} \mathrm{C}$ is not enough to completely transform the surface treatment induced $m-\mathrm{ZrO}_{2}$ for the $\mathrm{Y}-\mathrm{TZP} / \mathrm{Al}_{2} \mathrm{O}_{3}$ ZirTough (Kuraray Noritake) zirconia. We additionally heat-treated the ground $\mathrm{Y}-\mathrm{TZP} / \mathrm{Al}_{2} \mathrm{O}_{3}$ ZirTough (Kuraray Noritake) zirconia at $1450{ }^{\circ} \mathrm{C}$ and still could not detect $m-\mathrm{ZrO}_{2}$. The surface-phase composition of the ground and heat-treated (at $1450^{\circ} \mathrm{C}$ ) $\mathrm{Y}-\mathrm{TZP} / \mathrm{Al}_{2} \mathrm{O}_{3}$ ZirTough (Kuraray Noritake) zirconia was the same as that of the as sintered (untreated) $\mathrm{Y}-\mathrm{TZP} / \mathrm{Al}_{2} \mathrm{O}_{3}$ ZirTough (Kuraray Noritake) zirconia.

Stress analysis of surface-treated zirconia can be performed by X-ray diffraction $[10,23]$ or micro-Raman spectroscopy [24]. According to Pezzotti and Porporati, microRaman peaks shift linearly with the magnitude of the residual stress level [19]. The peak shift of the tetragonal band around $147 \mathrm{~cm}^{-1}$ was assessed because this tetragonal peak does 



Fig. 2 - (a) Graph showing the Weibull analysis for the different surface-treated Y-TZP LAVA Plus (3M ESPE) zirconia. Higher scale parameters were recorded for the 'GROUND', 'GROUND + $\mathrm{Al}_{2} \mathrm{O}_{3}$ SANDBLASTED' and 'GROUND + CoJet SANDBLASTED' zirconia than for the 'GROUND + HEAT' treated zirconia. On the other hand, a higher shape parameter was recorded for the 'GROUND + HEAT' treated zirconia than for the other surface-treated zirconia. (b) Graph showing the Weibull analysis for the different surface-treated $\mathrm{Y}-\mathrm{TZP} / \mathrm{Al}_{2} \mathrm{O}_{3} \mathrm{ZirTough}$ (Kuraray Noritake) zirconia. The trends were similar as to those for Y-TZP LAVA Plus (3M ESPE) zirconia. Overall, higher shape parameters were obtained for $\mathrm{Y}-\mathrm{TZP} / \mathrm{Al}_{2} \mathrm{O}_{3} \mathrm{ZirTough}$ (Kuraray Noritake) zirconia than for Y-TZP LAVA Plus (3M ESPE) zirconia.

\section{Table 2 - Summary of the $m-\mathrm{ZrO}_{2}$ volume fraction and the four-point bending strength Weibull analysis results.}

\begin{tabular}{|c|c|c|c|c|c|c|}
\hline Zirconia & $\begin{array}{l}\text { Surface } \\
\text { treatment }\end{array}$ & $\mathrm{n}$ & $\begin{array}{l}m-\mathrm{ZrO}_{2} \\
\text { volume } \\
\text { fraction (\%) }\end{array}$ & $\begin{array}{l}\text { Weibull } \\
\text { modulus } \\
m^{1}\end{array}$ & $\begin{array}{l}\text { Characteristic } \\
\text { strength } \sigma_{0}^{2} \\
\text { (B63.2) }\end{array}$ & $\begin{array}{l}\text { 95\% confidence } \\
\text { level at } \sigma_{0}{ }^{3} \\
\text { (B63.2) }\end{array}$ \\
\hline Y-TZP LAVA Plus (3M & 'GROUND' & 10 & 3.5 & 6.2 & 1192 & $1061-1348(a b)$ \\
\hline \multirow[t]{3}{*}{ ESPE) zirconia } & 'GROUND + HEAT' & 9 & 0 & 9.4 & 934 & $862-1017$ (c) \\
\hline & 'GROUND + $\mathrm{Al}_{2} \mathrm{O}_{3}$ SANDBLASTED' & 9 & 10.9 & 13.0 & 1107 & $1042-1178(b)$ \\
\hline & ‘GROUND + CoJet SANDBLASTED’ & 10 & 6.9 & 7.1 & 1149 & $1041-1276(a b)$ \\
\hline $\mathrm{Y}-\mathrm{TZP} / \mathrm{Al}_{2} \mathrm{O}_{3}$ & ‘GROUND’ & 10 & 37.2 & 11.3 & 1237 & $1174-1304(a b)$ \\
\hline ZirTough (Kuraray & ‘GROUND + HEAT’ & 10 & 13.9 & 24.7 & 994 & $966-1026$ (c) \\
\hline \multirow[t]{2}{*}{ Noritake) zirconia } & 'GROUND + $\mathrm{Al}_{2} \mathrm{O}_{3}$ SANDBLASTED' & 10 & 36.5 & 19.9 & 1262 & $1218-1311(a)$ \\
\hline & ‘GROUND + CoJet SANDBLASTED’ & 10 & 35.6 & 15.3 & 1212 & $1156-1274(a b)$ \\
\hline
\end{tabular}

not overlap with any $m-\mathrm{ZrO}_{2}$ bands [25]. A peak shift of this tetragonal band toward a higher wavelength corresponds to the presence of a residual compressive stress [19]. For both zirconia grades, micro-Raman analysis showed a clear peak shift toward a higher wavelength for the $t-\mathrm{ZrO}_{2}$ phase for the three surface-treated ('GROUND', 'GROUND $+\mathrm{Al}_{2} \mathrm{O}_{3}$ SANDBLASTED' and 'GROUND + CoJet SANDBLASTED') zirconia. 'Ground + HEAT' treated zirconia showed a similar peak position as for the as sintered (untreated) zirconia, which can be assumed to be the 'stress-free' condition. The correlation between the $\mathrm{t}-\mathrm{ZrO}_{2}$ peak position due to the residual compressive stress level and the characteristic four-point bending strength was clear and significant for both zirconia grades $\left(\mathrm{R}^{2}=0.97, p=0.0155\right.$ for Y-TZP LAVA Plus (3M ESPE) zirconia, $\mathrm{R}^{2}=0.933, p=0.0338$ for $\mathrm{Y}-\mathrm{TZP} / \mathrm{Al}_{2} \mathrm{O}_{3}$ ZirTough (Kuraray Noritake) zirconia), as presented in Fig. $3 a$ and b. Wulfman et al. assessed the sampling depth of micro-Raman spectroscopy.
According to them, probes based on $10 \times$ objective penetrated up to $68 \mu \mathrm{m}$, whereas those based on the $80 \times$ objective were limited to $5 \mu \mathrm{m}$ [26]. Their results indicate that in our setting (100x objective), the sampling depth of micro-Raman spectroscopy would be less than $5 \mu \mathrm{m}$.

Moreover, the depth of the residual compressive stress was assessed using confocal micro-Raman spectroscopy, as shown in Fig. $3 \mathrm{c}$ and d. For Y-TZP/Al ${ }_{2} \mathrm{O}_{3}$ ZirTough (Kuraray Noritake) zirconia, grinding, $\mathrm{Al}_{2} \mathrm{O}_{3}$ - and CoJet-sandblasting created a deeper residual compressive stress zone (up to $8 \mu \mathrm{m}$ deep) than for the Y-TZP LAVA Plus (3M ESPE) zirconia (up to about $4 \mu \mathrm{m}$ deep). The thicker compressive stress layer at the surface of the $\mathrm{Y}-\mathrm{TZP} / \mathrm{Al}_{2} \mathrm{O}_{3}$ ZirTough (Kuraray Noritake) zirconia can be directly related to the higher Weibull modulus, as compared to that at the surface of the Y-TZP LAVA Plus (3M ESPE) zirconia. 
a Y-TZP LAVA Plus (3M ESPE) zirconia

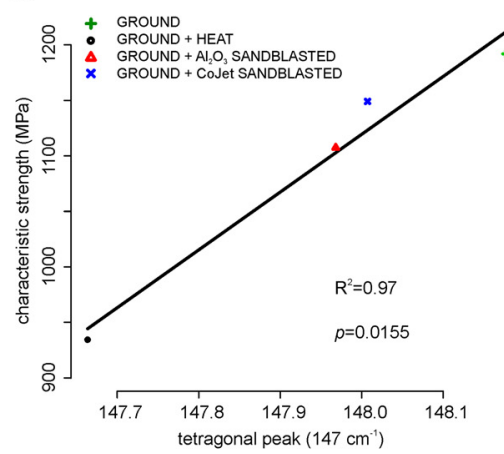

\section{C}

Y-TZP LAVA Plus (3M ESPE) zirconia

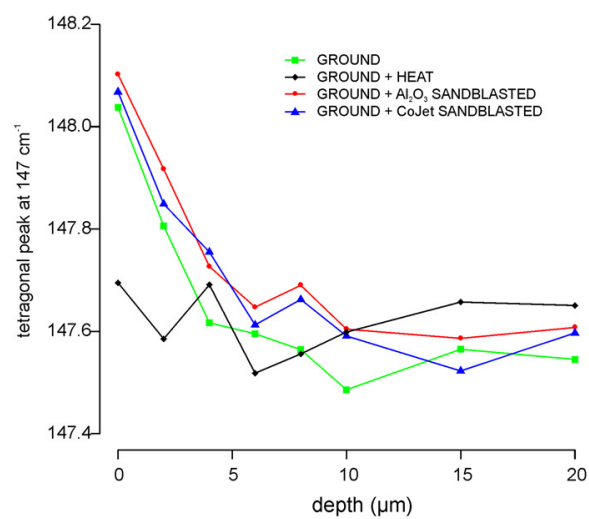

(b) Y-TZP/Al ${ }_{2} \mathrm{O}_{3}$ ZirTough (Kuraray Noritake) zirconia

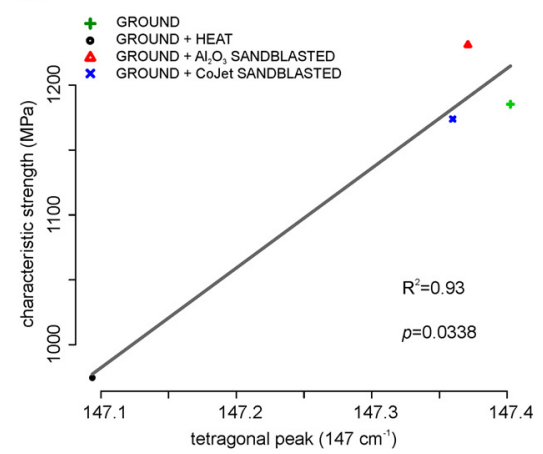

a

Y-TZPIAl $\mathrm{O}_{3}$ ZirTough (Kuraray Noritake) zirconia

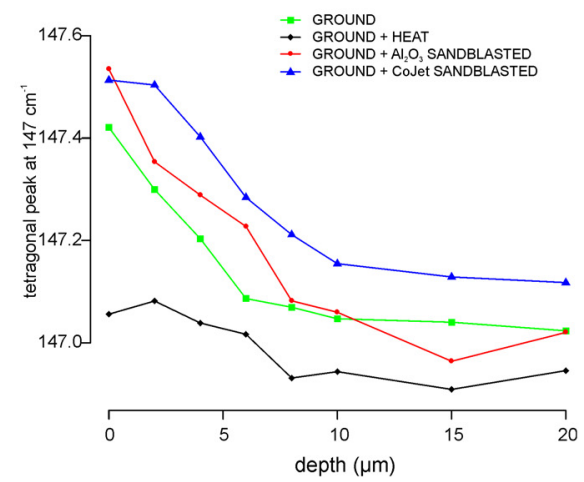

Fig. 3 - (a) Summary of correlation analysis for Y-TZP LAVA Plus (3M ESPE) zirconia. The average of the detected distinct peak shift of the tetragonal $\mathrm{ZrO}_{2}$ band around $147 \mathrm{~cm}^{-1}$ was measured after surface treatment. Correlation analysis revealed that a larger peak shift, i.e., a higher compressive stress in the surface layer, resulted in higher four-point bending strength $\left(\mathrm{R}^{2}=0.97, p=0.0155\right)$. (b) Summary of correlation analysis for Y-TZP/Al $\mathrm{O}_{3}$ ZirTough (Kuraray Noritake) zirconia. The average of the detected distinct peak shift of the tetragonal $\mathrm{ZrO}_{2}$ band around $147 \mathrm{~cm}^{-1}$ was measured after surface treatment. Correlation analysis revealed that a larger peak shift, i.e., a higher compressive stress in the surface layer, resulted in higher four-point bending strength $\left(R^{2}=0.93, p=0.0338\right)$. (c) and (d) Evolution of the $t-\mathrm{ZrO}_{2}$ peak position as a function of depth from the surface. 'GROUND', ' $\mathrm{Al}_{2} \mathrm{O}_{3}$ SANDBLASTED' or 'CoJet SANDBLASTED' Y-TZP/ $\mathrm{Al}_{2} \mathrm{O}_{3}$ ZirTough (Kuraray Noritake)

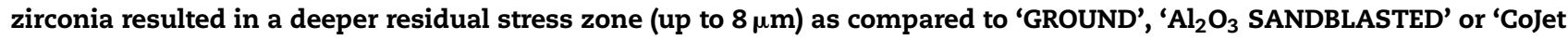
SANDBLASTED' Y-TZP LAVA Plus (3M ESPE) zirconia (up to $4 \mu \mathrm{m}$ ).

Literature on actual residual stress measurement of surface-treated zirconia using micro-Raman spectroscopy is scarce [24]. A higher residual compressive surface-stress level was measured on a surface-treated (SiC-sandblasted) Ce$\mathrm{TZP} / \mathrm{Al}_{2} \mathrm{O}_{3}$ zirconia compared to a Y-TZP zirconia, this most probably due to the higher transformability of $\mathrm{Ce}-\mathrm{TZP} / \mathrm{Al}_{2} \mathrm{O}_{3}$ zirconia, whereas a significantly lower residual stress was measured for heat-treated Y-TZP and Ce-TZP/ $/ \mathrm{Al}_{2} \mathrm{O}_{3}$ zirconia [24]. The latter is in line with our present results. Heat treatment caused $m-\mathrm{ZrO}_{2}$ to $\mathrm{t}-\mathrm{ZrO}_{2}$ phase transformation and compressive stress release, resulting in a concomitant decreased flexural strength of zirconia [3].

The four-point bending strength data were analyzed using Weibull statistics. The Weibull distribution is a continuous probability distribution; Weibull survival analysis has been developed to determine the level of structural reliability of materials [27-29]. Several studies have indeed applied Weibull analysis to assess the reliability of the mechanical properties of dental zirconia [10-12,16,30]. The main difference with other statistical approaches is that the distribution of the failures is not determined before, but is estimated from the data. The main advantage is that not only information regarding bending strength is gathered, but also the reliability of the outcome is estimated. Each Weibull analysis is characterized by two principal parameters, the Weibull "shape" or modulus $(m)$, and the Weibull "scale", or the B63.2 parameter or characteristic strength $\left(\sigma_{0}\right)$.

Applied to this work, the higher the Weibull modulus $m$, the more reliable the zirconia in terms of mechanical properties; the higher the characteristic strength $\sigma_{0}$, the higher the actual bending strength. Although the $\sigma_{0}$ was similar for both zirconia grades, Weibull moduli were clearly different. The Weibull modulus as a function of the applied surface treatment of the $\mathrm{Y}-\mathrm{TZP} / \mathrm{Al}_{2} \mathrm{O}_{3}$ ZirTough (Kuraray Noritake) zirconia ranged from 11.3 to 24.7, whereas that of the Y-TZP LAVA Plus (3M ESPE) zirconia varied from 6.2 to 13.0 (see Table 2). 
The three surface-treated zirconia ('GROUND', 'GROUND $+\mathrm{Al}_{2} \mathrm{O}_{3}$ SANDBLASTED' and 'GROUND + CoJet SANDBLASTED') resulted in a comparable high characteristic strength, which was substantially higher than that for the 'GROUND + HEAT' treated zirconia. The Weibull modulus of the 'GROUND' zirconia however was the lowest. These two trends are in line with previous studies, which assessed the mechanical properties of ground or $\mathrm{Al}_{2} \mathrm{O}_{3}$-sandblasted dental zirconia with/without additional heat treatment using a biaxial flexural strength test $[9,12]$.

Additional $\mathrm{Al}_{2} \mathrm{O}_{3}$-sandblasting or tribochemical silica (CoJet) sandblasting after grinding resulted in a higher Weibull modulus compared to that for the 'GROUND' zirconia. This is most probably due, at least in part, to the smoothening effect of the additional sandblasting, which removes grinding marks and micro-cracks that may otherwise act as stress concentrators [31]. In addition, this could also in part be attributed to the deeper and possibly more continuous layer that is subjected to a compressive stress state after sandblasting, as was revealed by micro-Raman analysis.

The tribochemical silica (CoJet) sandblasting is more gentle, as compared to $\mathrm{Al}_{2} \mathrm{O}_{3}$-sandblasting, which resulted in a limited increase in Weibull modulus (Fig. 1). The size of the surface flaws, which were introduced by sandblasting, did not seem to have exceeded the thickness of the compressive surface layer, since the strength of the material was not reduced [12]. Moreover, Chintapalli et al. reported that sandblasting using a smaller particle size $(110 \mu \mathrm{m})$ did not produce additional micro-cracks at the zirconia surface [32]. Grinding, on the other hand, was shown to produce micro-cracks at the zirconia surface [33].

Although the nature of the flaws in the 'GROUND' zirconia and 'GROUND + HEAT' zirconia should be the same, the 'GROUND + HEAT' zirconia grades had a significantly lower characteristic strength, but higher Weibull modulus. This is most probably due to the residual compressive stress zone at the surface of the ground zirconia [33]. In the present study, ZirTough (Kuraray Noritake) is an $\mathrm{Y}-\mathrm{TZP} / \mathrm{Al}_{2} \mathrm{O}_{3}$ zirconia that contains $\leq 10 \mathrm{wt} \% \mathrm{Al}_{2} \mathrm{O}_{3}$ as a secondary phase. The addition of $\mathrm{Al}_{2} \mathrm{O}_{3}$ to Y-TZP zirconia induces a smaller grain size, as compared to that of Y-TZP zirconia, which results in a smaller flaw size as compared to Y-TZP zirconia [34]. This effect is more obvious when Y-TZP- $\mathrm{Al}_{2} \mathrm{O}_{3}$ zirconia receives an additional HIP (hot isostatic pressing) treatment, as the HIP treatment also reduces the porosity of $\mathrm{Y}-\mathrm{TZP} / \mathrm{Al}_{2} \mathrm{O}_{3}$ zirconia [35]. In the present study, however, the Y-TZP/Al $\mathrm{A}_{2} \mathrm{O}_{3}$ ZirTough (Kuraray Noritake) zirconia was not HIP-ed, but the size of the $\mathrm{Al}_{2} \mathrm{O}_{3}$ grains was relatively large (around $500 \mathrm{~nm}$ ), having resulted in a comparable characteristic bending strength level as for the Y-TZP LAVA Plus (3M ESPE) zirconia. Nevertheless, the additional $\mathrm{Al}_{2} \mathrm{O}_{3}$ phase resulted in a higher reliability in bending strength, as compared to that of the Y-TZP zirconia.

\section{Conclusion}

Surface grinding with or without additional $\mathrm{Al}_{2} \mathrm{O}_{3}$ or tribochemical silica (CoJet) sandblasting induced residual compressive stress at the zirconia surface, and resulted in a comparable characteristic four-point bending strength of the
Y-TZP LAVA Plus (3M ESPE) zirconia and the Y-TZP/Al $\mathrm{O}_{3}$ ZirTough (Kuraray Noritake) zirconia. Surface grinding with or without additional $\mathrm{Al}_{2} \mathrm{O}_{3}$ or tribochemical silica (CoJet) sandblasting for $\mathrm{Y}-\mathrm{TZP} / \mathrm{Al}_{2} \mathrm{O}_{3}$ ZirTough (Kuraray Noritake) zirconia resulted in a deeper compressive stress zone than for Y-TZP LAVA Plus (3M ESPE) zirconia, that on its turn resulted in an increased Weibull modulus and concomitantly increased zirconia reliability in terms of mechanical properties. Thermal treatment after grinding however eliminated the presence of the residual compressive stress surface layer, and resulted in a decrease of the characteristic strength by approximately $200 \mathrm{MPa}$.

\section{Acknowledgements}

M.I. acknowledges the Flemish scholarship for Japanese students. This work was performed within the framework of the Research Fund of KU Leuven provided for the project 'OT/10/052' and of the Research Foundation Flanders (FWOFlanders) Fund for the project 'G.0431.10'.

\section{REFERENCES}

[1] Kosmac T, Kocjan A. Ageing of dental zirconia ceramics. J Eur Ceram Soc 2012;32:2613-22.

[2] Miyazaki T, Nakamura T, Matsumura H, Ban S, Kobayashi T. Current status of zirconia restoration. J Prosthodont Res 2013;57:236-61.

[3] Kosmac T. The effects of dental grinding and sandblasting on ageing and fatigue behavior of dental zirconia (Y-TZP) ceramics. J Eur Ceram Soc 2008;28:1085-90.

[4] Inokoshi M, De Munck J, Minakuchi S, Van Meerbeek B. Meta-analysis of bonding effectiveness to zirconia ceramics. J Dent Res 2014;93:329-34.

[5] Thompson JY, Stoner BR, Piascik JR, Smith R. Adhesion/cementation to zirconia and other non-silicate ceramics: where are we now? Dent Mater 2011;27:71-82.

[6] Ban S, Sato H, Suehiro Y, Nakanishi H, Nawa M. Effect of sandblasting and heat treatment on biaxial flexure strength of the zirconia/alumina nanocomposite. Key Eng Mater 2007;330-332:353-6.

[7] Ban S, Sato H, Suehiro Y, Nakanishi H, Nawa M. Biaxial flexure strength and low temperature degradation of $\mathrm{Ce}-\mathrm{TZP} / \mathrm{Al}_{2} \mathrm{O}_{3}$ nanocomposite and Y-TZP as dental restoratives. J Biomed Mater Res B 2008;87:492-8.

[8] Ban S, Sato H, Suehiro Y, Nakanishi H, Nawa M. Effect of sintering condition, sandblasting and heat treatment on biaxial flexure strength of zirconia. Key Eng Mater 2008;361-363:779-82.

[9] Guazzato M, Quach L, Albakry M, Swain MV. Influence of surface and heat treatments on the flexural strength of Y-TZP dental ceramic. J Dent 2005;33:9-18.

[10] Ho C-J, Liu H-C, Tuan W-H. Effect of abrasive grinding on the strength of Y-TZP. J Eur Ceram Soc 2009;29:2663-7.

[11] Karakoca S, Yilmaz H. Influence of surface treatments on surface roughness, phase transformation, and biaxial flexural strength of Y-TZP ceramics. J Biomed Mater Res B 2009;91:930-7.

[12] Kosmac T, Oblak C, Jevnikar P, Funduk N, Marion L. The effect of surface grinding and sandblasting on flexural strength and reliability of Y-TZP zirconia ceramic. Dent Mater 1999;15:426-33. 
[13] Papanagiotou HP, Morgano SM, Giordano RA, Pober R. In vitro evaluation of low-temperature aging effects and finishing procedures on the flexural strength and structural stability of Y-TZP dental ceramics. J Prosthet Dent 2006;96: 154-64.

[14] Sato H, Ban S, Nawa M, Suehiro Y, Nakanishi H. Effect of grinding, sandblasting and heat treatment on the phase transformation of zirconia surface. Key Eng Mater 2007;330-332:1263-6.

[15] Amaral M, Valandro LF, Bottino MA, Souza RO. Low-temperature degradation of a Y-TZP ceramic after surface treatments. J Biomed Mater Res B 2013;101:1387-92.

[16] Scherrer SS, Cattani-Lorente M, Yoon S, Karvonen L, Pokrant S, Rothbrust F, et al. Post-hot isostatic pressing: a healing treatment for process related defects and laboratory grinding damage of dental zirconia? Dent Mater 2013;29:e180-90

[17] Souza RO, Valandro LF, Melo RM, Machado JP, Bottino MA, Ozcan M. Air-particle abrasion on zirconia ceramic using different protocols: effects on biaxial flexural strength after cyclic loading, phase transformation and surface topography. J Mech Behav Biomed Mater 2013;26:155-63.

[18] Yongqi Z, Li J, Jingchao Z, Yunmao L, Junjun L, Wei L. Influence of different surface treatments on computer-aided design and manufacturing (CAD-CAM) zirconia frameworks. Sci Res Essays 2012;7:957-62.

[19] Pezzotti G, Porporati AA. Raman spectroscopic analysis of phase-transformation and stress patterns in zirconia hip joints. J Biomed Opt 2004;9:372-84.

[20] Tabares JAM, Anglada MJ. Quantitative analysis of monoclinic phase in 3Y-TZP by Raman spectroscopy. J Am Ceram Soc 2010;93:1790-5.

[21] Wojdyr M. Fityk: a general-purpose peak fitting program. J Appl Crystallogr 2010;43:1126-8.

[22] Symynck J, De Bal F. Monte Carlo pivotal confidence bounds for Weibull analysis, with implementations in R. New Technol Prod Mach Manuf Technol 2011:43-50.

[23] Bhargava S, Doi H, Kondo R, Aoki H, Hanawa T, Kasugai S. Effect of sandblasting on the mechanical properties of Y-TZP zirconia. Biomed Mater Eng 2012;22:383-98.
[24] Sato H, Yamada K, Pezzotti G, Nawa M, Ban S. Mechanical properties of dental zirconia ceramics changed with sandblasting and heat treatment. Dent Mater J 2008;27:408-14.

[25] Pezzotti G. Raman piezo-spectroscopic analysis of natural and synthetic biomaterials. Anal Bioanal Chem 2005;381:577-90.

[26] Wulfman C, Djaker N, Dupont N, Ruse D, Sadoun M, la Chapelle ML. Raman spectroscopy evaluation of subsurface hydrothermal degradation of zirconia. J Am Ceram Soc 2012:95:2347-51.

[27] Basu B, Tiwari D, Kundu D, Prasad R. Is Weibull distribution the most appropriate statistical strength distribution for brittle materials? Ceram Int 2009;35:237-46.

[28] Quinn JB, Quinn GD. A practical and systematic review of Weibull statistics for reporting strengths of dental materials. Dent Mater 2010;26:135-47.

[29] Weibull W. A statistical distribution function of wide applicability. J Appl Mech 1951;18:293-7.

[30] Kosmac T, Oblak C, Jevnikar P, Funduk N, Marion L. Strength and reliability of surface treated Y-TZP dental ceramics. J Biomed Mater Res 2000;53:304-13.

[31] Scherrer SS, Cattani-Lorente M, Vittecoq E, de Mestral F, Griggs JA, Wiskott HWA. Fatigue behavior in water of Y-TZP zirconia ceramics after abrasion with $30 \mu \mathrm{m}$ silica-coated alumina particles. Dent Mater 2011;27:E28-42

[32] Chintapalli RK, Marro FG, Jimenez-Pique E, Anglada M. Phase transformation and subsurface damage in 3Y-TZP after sandblasting. Dent Mater 2013;29:566-72.

[33] Munoz-Tabares JA, Jimenez-Pique E, Reyes-Gasga J, Anglada M. Microstructural changes in ground 3Y-TZP and their effect on mechanical properties. Acta Mater 2011;59:6670-83.

[34] Tsukuma K, Takahata T. Mechanical property and microstructure of TZP and TZP/ $\mathrm{Al}_{2} \mathrm{O}_{3}$ composites. Adv Struct Ceram Symp 1987:123-35.

[35] Tsukuma K, Ueda K, Shimada M. Strength and fracture-toughness of isostatically hot-pressed composites of $\mathrm{Al}_{2} \mathrm{O}_{3}$ and $\mathrm{Y}_{2} \mathrm{O}_{3}$-partially-stabilized $\mathrm{ZrO}_{2}$. J Am Ceram Soc 1985;68:C4-5. 